\title{
Using Blockchain as a Platform for Smart Cities
}

Christian Nãsulea, Stelian-Mihai Mic

University of Bucharest, Bucharest

Romania

christian@nasulea.ro

stelian.mic@miclawoffice.eu

ABSTRACT: Objectives: Incorporating new technologies into the development of smart cities means rethinking the way different services are provided. From this perspective, Blockchain might represent the future of both smart cities and smart communities as it offers new alteratives for individuals and institutions.

Prior Work: Blockchain was mainly perceived through its linkage with bitcoin, but recent developments have started exploring the idea of using it for financial transactions, logistics and securing contracts. Tapscott \& Tapscott (2016)have acknowledged the potential the Blockchain Revolution had on redefining the idea of trust in both digital and local communities. Blockchain technology has the ability to enhance transparency of local and regional institutions while also making it easier to communicate sensitive data without compromising security and privacy.

Approach: We look at the different fields blockchain can have an impact on and we try to assess the viability of moving towards an integrated platform for intermediating day-to-day activities between both institutions and individuals. We will assess the advantages of digitizing and securing public and private data while also considering the potential risks this process might involve.

Results: We aim to create a model of how blockchain might work in communities and assess its impact on the overall economic and human development indicators.

Implications: Public administrators in many countries are starting to acknowledge blockchain's potential in solving problems for local communities our results will be a valuable starting point for developing local initiatives for using blockchain as a platform for communications and transactions. Furthermore, a smart city must be a city where individuals can interact and solve their issues quickly, using digital technologies for increased efficiency.

Value: Blockchain is thought to be the future of managing both public and private affairs. Countries such as Dubai, Singapore and China are incorporating blockchain technology into developing smart cities. Blockchain makes us rethink many of the different aspects of how communities can be organized, offering new alternatives and promising a more transparent and efficient economic model.

Keywords: Digital Era, Economic Model, IoT, Technology

DOI: $10.6025 /$ jet/2018/9/2/37-43 
Received: 12 January 2018, Revised 9 February 2018, Accepted 18 February 2018

(C) 2018 DLINE. All Rights Reserved

\section{Introduction}

Many cities wish to become Smart Cities. Soon most cities will pride themselves with being a Smart City. While we don't know yet what criteria a city should meet in order to be deemed smart we're already looking for ways to make Smart Cities smarter, to enhance their capabilities thus making them the smartest. Researchers in academia, technology developers, and city managers are all looking for the best technologies to integrate in order to enhance and optimize cities.

In this paper we will turn to Blockchain as a revolutionary, disruptive technology that promises to change the way we interact in our cities and communities. We emphasize the distinction between Smart City and Smart Community and look to the advantages that can be drawn from the technology by individuals and organizations, by private and public actors, by individuals and communities.

\subsection{Structure}

We will review existing literature with regards to Blockchain and Smart Cities. The most adequate applications of Blockchain technology will then be discussed in more detail, setting the basis for their inclusion in a proposed model. The model proposal will integrate the applications identified in previous steps in a way that will maximize enhancements to existing Smart City models. Conclusions will be drawn based on economic efficiency and legal aspects.

\subsection{Prior Work}

An increasing number of research papers and books (Tapscott \& Tapscott, 2016) have looked into Blockchain as a solution to a variety of problems over the past 10 years. The pace of this increase has accelerated proportionally with the recent rapid increase in Bitcoin to USD or Bitcoin to EUR exchange rate. Initially, Bitcoin was widely dismissed as a fad. Its endurance, unexpected to many, is the perfect promoter for Blockchain, Bitcoin's underlying shared ledger technology, catalyzing interest and bringing more people into the fan-base and more investors into the business of developing solutions. These days it's not just about Bitcoin or Blockchain anymore as new technologies and variations of technologies are appearing and are being explored constantly (Migirov \& Garcia, 2016).

Finding new applications for Blockchain has naturally connected the technology to the emerging field of Smart Cities (Sun, Yan, \& Zhang, 2016) (Ibba, Pinna, Seu, \& Pani, 2017). As both fields are very promising researchers are looking into everything from Smart Roads (Sharma, Moon, \& Park, 2017) to Smart Contracts (Watanabe, et al., 2016) and the future of banking (Peters \& Panayi, 2016) and healthcare (Linn \& M., 2016).

Extensive research is being conducted into security issues related to Blockchain (Biswas \& Muthukkumarasamy, 2016) resolving issues identified in existing instances (Luu, Chu, Olickel, Saxena, \& Hobor, 2016) or preventing the appearance of others well before the systems that would be vulnerable to them even come into existence (Kshetri, 2017).

There are already a number of large scale implementations in Smart Cities. China has taken huge steps towards developing Blockchain-based solutions for its Smart Cities (Guo, Liu, Yu, Hu, \& Sang, 2016). Of course, what is being referred to as a Smart City will differ greatly from case to case. Dubai is turning towards Blockchain to keep its competitive edge in business by exploring the concept of e-Democracy (Karmakar \& Sahib).

Other case studies are focusing on particular sectors of the economy. Moldova's tourism and healthcare sectors are connected in a study by Pilkington (2017). While this particular case study is not directly connected to the concept of Smart Cities the ideas themselves are directly applicable. In a similar way, applications in voting technology (Davidson, De Filippi, \& Potts, 2016) and legal support systems (Wright \& De Filippi, 2015) can have a huge impact on future Smart Cities.

\subsection{Methodology}

By relying on the results of prior research and on the wealth of concept papers presenting the vast possibilities of Blockchain and Smart technologies we have analyzed the viability of dozens of potential applications for Blockchain ledgers. Possible applications were analyzed from economic efficiency, legal compliance, and security risk points of view. The four most promising

\begin{tabular}{lllll}
\hline 38 & Journal of E - Technology Volume & 9 & Number 2 & May 2018 \\
\hline
\end{tabular}


applications are presented in more detail in this paper and are subsequently integrated into a proposed model for Blockchain use. The model was developed using the Basic Model Building Method, without experimental design.

\section{Potential Applications for Blockchain Technology in Smart Cities}

Through its persistent and at the same time private storage of data, Blockchain enables the development of a large number of new models of interaction that could not even be conceived of before the advent of the technology. In the following sections we will briefly describe a few possible applications.

\subsection{Smart Contracts}

Agreements between two or more parties are usually recorded through contracts. In order to satisfy the requirements of the parties involved contracts must describe the terms of those agreements in great detail, which means they will be extensive and complex and will probably need to be drafted by lawyers, which will also make them costly to the aforementioned parties. Many interactions within a community, from property sales to marriage, will involve some form of contract.

Making sure a contract is upheld requires mutual recognition of the terms agreed upon in the contract, which has traditionally been achieved through the use of co-signatory witnesses and by separate copies being handed over to each party involved in the signing process, including the witnesses.

Blockchain has the potential to make contracts stronger and more accessible. The terms of a contract would be effectively tamper proof as their content could be verified privately through hashed crypto keys saved in a ledger shared not only by the signatory parties but by all members of the community making use of the blockchain-based contract system. Only the parties involved in the signing of the contract would retain actual knowledge of the terms but the authenticity of those terms could be verified by any third party using the shared ledger by simply hashing the terms again and comparing the resulting cryptographic key with the one in the ledger (USA Patent No. 15/594,364, 2017). By further registering the hashed crypto keys with additional Blockchains additional security is given to the contracts, easing concerns stemming from potential implementation problems associated to Blockchain-based solutions (Luu, Chu, Olickel, Saxena, \& Hobor, 2016).

The use of Blockchain alone does not automatically bring reduced contracting costs. However, significant reductions in cost can be achieved by using Blockchain in conjunction with other technologies. Contract template services have been around for many years and, more recently, through the application of Artificial Intelligence to Smart Contracts we are seeing the first viable models for dynamic automated contract generation (Omohundro, 2014). By standardizing parts of contracts, by hand or by AI, it is possible to authenticate sub-components of the contracts allowing further development and flexibility to the Smart Contract model as well as additional reductions in cost.

In some countries, the use of Blockchain-certified contracts would bring an additional reduction in cost associated with the use of notaries, another branch of the legal profession that adds costly overheads to current contracting practices. Securing contracts using Blockchain is not just viable replacement for the use of notaries, it would also mean an improvement in speed, convenience and reliability of the certification process.

\subsection{Smart Assets}

Expanding on the Smart Contracts with sub-components idea some technology developers are working on creating the IT infrastructure required to improve the transition of products through the supply chains of the world. This is not the same idea of "smart assets" that was proposed in the early 2000's, which presumed that assets would become smart by integrating RFID instead of traditional barcode identifiers (Lampe \& Strassner, 2003). The idea itself has evolved (Bughin, Chui, \& Manyika, 2010) incorporating Blockchain as a solution for cloud-based tracking of Smart Assets. Products and their individual components would be permanently monitored along the supply chain by updating a predefined set of characteristics thus providing information to distribution systems about their availability in real time. Better information means increased availability and optimized transport of items to where they are needed.

But what would be the role of Smart Assets in a Smart City? After all, the Smart Asset model we are discussing is particularly well adapted to merchandise storage and distribution, and storage tends to increasingly take place outside of cities. Increasing efficiency in distribution by turning itemized products into Smart Assets should have a tremendous effect on the use of space in the city. Less space will be required for storage in the city as inventory management and storage could one day switch 
completely from Just In Case (JIC) to Just In Time (JIT). As more space is made available by optimizing distribution we can expect Smart Cities to benefit from more diversity of products, more availability of green space, or new innovative functions for old storage spaces.

We must not limit ourselves to thinking of Smart Assets as products. For example, in a Smart City parking spaces can be Smart Assets too (Zhang \& Wen, 2017). Blockchain can provide the basis for the development of a market-based system that would allow drivers or driverless cars to ensure there is an available parking spot at their destination. By using Blockchain to store the data about parking spot reservations automated systems could enforce those reservations and punish parking offenders. Additionally, by using a differentiated pricing system for parking places, another automated system could pursue a more optimal distribution of traffic by directing drivers who value parking spot proximity more than others to premium, high demand parking areas, while keeping the others in areas with lower demand. A Blockchain-based system would ensure the accuracy of the optimization process.

An additional distinction needs to be made between Smart Assets, as described above, and what we now call Smart Devices, as components of Smart Homes using Internet-of-Things (IoT) technology to perform smart functions (Nasulea \& Moroianu, 2016). The two do share some important common characteristics, which might generate confusion. They both connect to the Internet and they both rely on various forms of cloud-based technologies. However, Smart Devices have the capacity to perform actions on their own while not all Smart Assets perform actions of their own. Rather, Smart Assets simply require the possibility to have things done to them.

\subsection{Digital Identity}

Digital Identities created using a Blockchain protocol are already available and can be used as electronic signatures. The most notable example right now is the Estonian e-Residency programme (Republic of Estonia e-Residency, 2017) which enables users to create a Digital Identity that can be used to set up a business in Estonia by non-EU citizens.

Combining Digital Identities with Smart Assets means we can authorize things that we own, that are registered on the Blockchain, to initiate transactions on our behalf. The heating system in the house can pay its corresponding utility bill, the fridge can order milk when milk is running out, the car can schedule itself for its annual check-up and so on. Smart Assets that do not possess AI but are registered to the Blockchain would still present us with benefits, as ownership over those assets would be easy to identify. A forgotten umbrella would make its way back to its owner eventually, theft would be diminished as various items would be easier to trace back to their rightful owners.

\subsection{Voting}

Blockchain's primary advantage, of being both secure and private at the same time, means citizens could be asked to authenticate using their Digital Identity in order to vote in local, regional or national elections from the comfort of their own homes. The actual vote would not be identifiable from the Blockchain but the vote count and the legitimacy of the voters would be verifiable. Any citizen using the Blockchain would be able to independently audit the vote. The audit trail would clearly show that no votes were removed or changed and that all voters voted legally.

This idea challenges the very structure of human society by raising questions regarding the necessity of the state as a center of coordination for communities (Atzori, 2015). The Bitcoin Foundation started a project aiming to develop Blockchain-based voting systems in 2015 (Pilkington, 2016) and the Liberal Alliance in Denmark has already used Blockchain-based system for its internal elections (Poulsen, 2014). This type of voting would not only provide increased trust in the electoral process, it would also decrease the cost of voting to the point where far more decisions could be made directly by a constituency.

In a Smart City decisions don't even need to be the result of a vote. The traditional simple majority voting system can be replaced by decision systems requiring the agreement of a larger portion of the community or even of the entire community. Such systems can leave important decisions open for debate until the community reaches consensus (Nasulea \& Medintu, 2015). Blockchain technology is versatile enough to allow for variations of direct democracy that have never even been considered before.

\section{A model for Blockchain Integration in Smart Cities}

Blockchain enables relationships between individuals to function in a distributed manner, without the need for a coordinator or central planner. There are three main units within the model of a Blockchain-based Smart City that interact with each other

\begin{tabular}{llllll}
\hline 0 & Journal of E-Technology Volume 9 & Number 2 May 2018
\end{tabular}


through processes that shape the operational design of the system: The Smart City, the Smart Community, and the individual. At the individual layer implementations of Blockchain like Digital Identities or Smart Assets enhance and improve the life of the eCitizen of the Smart City. Smart Contracts and Blockchain-based voting, decision, and negotiation support systems enhance and optimize the operation of the Smart Community. Lastly, the Smart City itself reaps the benefits of increased efficiency from automated interactions with its e-Citizens and optimized distribution of Smart Assets. A model is presented in Figure 1 Blockchain at the center of enhanced Smart Cities and Smart Communities.

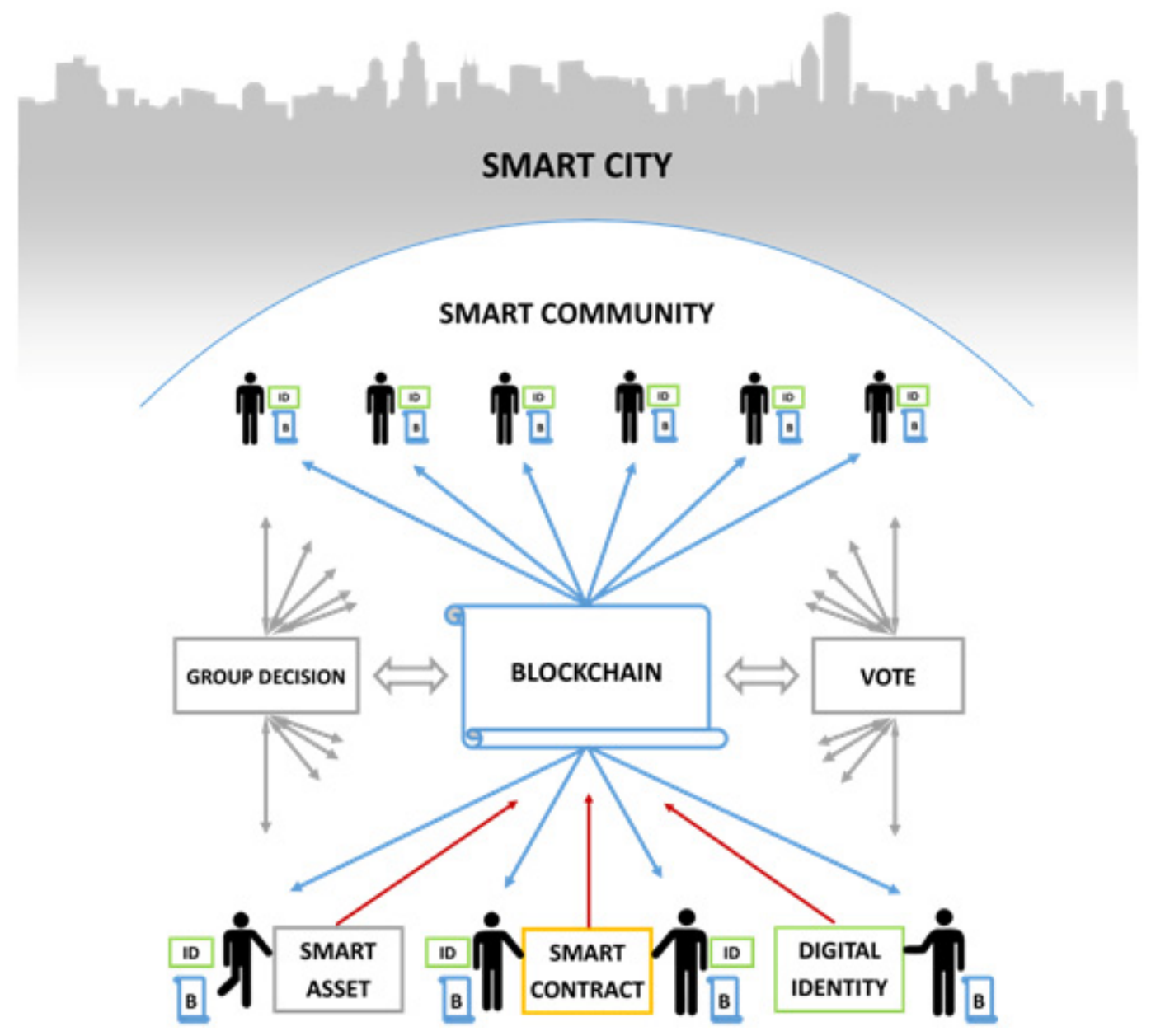

Figure 1. Blockchain at the center of enhanced Smart Cities and Smart Communities Source: own work

The Blockchain ledger lies at the center of the enhanced Smart City and Smart Community model. Access to the ledger is shared by all members of the community, with each member owning their own synchronized copy of the shared ledger (blue). Each member of the community has a Digital Identity which is used to authenticate the individual in transactions that involve the shared ledger (green). Creation of a new Digital Identity, Smart Contract, or Smart Asset is recorded in the Blockchain ledger (red). Smart Assets and group decisions are handled using the Blockchain ledger (gray).

While Blockchain technology can be used as a framework solution for a wide variety of issues faced by a Smart City the degree to which it is used in practice will depend on the preferences of the community and those of the city administration. Some cities may, in time, turn over control of most functions to new automated smart technologies while some will choose to retain control and rely on traditional city management solutions. Whatever the choice it is important to ensure that a broad spectrum of options is available to cities. Deregulation and transfer of powers from regional to local administration is essential to this end. There's very little point to discussing the benefit of Smart Contracts or Blockchain-based voting systems if national legislation mandates that contracts are only legally binding if they are undersigned by a notary or if electoral law requires citizens to put stamp to paper in all types of elections. 


\section{Conclusions}

Blockchain technology has enormous potential when it comes to shaping the enhanced Smart Communities of the future in ways that are more efficient and provide better quality of living. For technology to deliver on its promise it must be allowed to change the status quo. Blockchain is often referred to as a "disruptive" technology, a term that is often understood to have negative connotations, However, the only things to be negatively affected by the introduction of such new solutions are obsolete models of city management that need to be replaced, and will be replaced through innovation.

All truly revolutionary technologies are disruptive. We may even call them destructive, if we refer to the positive process of creative destruction (Schumpeter, 1942).

\section{References}

[1] Atzori, M. (2015). Blockchain technology and decentralized governance: Is the state still necessary? SSRN. doi:http:// dx.doi.org/10.2139/ssrn.2709713

[2] Biswas, K., Muthukkumarasamy, V. (2016). Securing Smart Cities Using Blockchain Technology. IEEE 14th International Conference on Smart Cities, (p. 1392-1393).

[3] Bughin, J., Chui, M., Manyika, J. (2010). Clouds, big data, and smart assets: Ten tech-enabled business trends to watch. McKinsey Quarterly, 56 (1) 75-86.

[4] Cuende, L. I., de Pedro Crespo, A. S. (2017). USA Patent No. 15/594,364.

[5] Davidson, S., De Filippi, P., Potts, J. (2016). Economics of blockchain.

[6] Guo, M., Liu, Y., Yu, H., Hu, B., Sang, Z. (2016). An overview of smart city in China. China Communications, 13(5).

[7] Ibba, S., Pinna, A., Seu, M., Pani, F. E. (2017). CitySense: blockchain-oriented smart cities. Proceedings of the XP2017 Scientific Workshops (p. 12). ACM.

[8] Karmakar, A., Sahib, U. (n.d.). (2017). SMART DUBAI: Accelerating Innovation and Leapfrogging E-Democracy. In EDemocracy for Smart Cities (p. 197-257). Singapore: Springer.

[9] Kshetri, N. (2017). Can Blockchain Strengthen the Internet of Things? IT Professional, 19(4) 68-72.

[10] Lampe, M., Strassner, M. (2003). The potential of RFID for moveable asset management. St. Gallen: Institute of Technology Management.

[11] Linn, L., M., K. (2016). Blockchain for health data and its potential use in health it and health care related research. Use of Blockchain for Healthcare and Research Workshop. .

[12] Luu, L., Chu, D.-H., Olickel, H., Saxena, P., Hobor, A. (2016). Making smart contracts smarter. In: Proceedings of the 2016 ACM SIGSAC Conference on Computer and Communications Security (p. 254-269). ACM.

[13] Migirov, R., Garcia, A. (2016, 10 7). A Smart City Built on Ethereum? International Blockchain Week Explores Viability and More. Retrieved from Consensys: https://media.consensys.net/a-smart-city-built-on-ethereum-international-blockchain-weekexplores-viability-and-more-a9aea91bd801

[14] Nasulea, C., Medintu, D. (2015). Testing Adaptivity in Negotiation Support Systems. Management, Research and Practice, $7(1), 32$.

[15] Nasulea, C., Moroianu, R.-M. (2016). Smart Homes and Economic Efficiency. Proceedings of the 10th International Conference on Business Excellence (pp. 192-200). Bucharest: Business Excellence.

[16] Omohundro, S. (2014). Cryptocurrencies, Smart Contracts, and Artificial Intelligence. AI Matters, 1(2), $19-21$.

[17] Peters, G. W., Panayi, E. (2016). Understanding modern banking ledgers through blockchain technologies: Future of transaction processing and smart contracts on the internet of money. Banking Beyond Banks and Money, 239-278.

[18] Pilkington, M. (2016). Blockchain technology: principles and applications. In: X. Olleros, \& M. Zhegu (Eds.), Research Handbook on Digital Transformations (p. 39). Edward Elgar.

[19] Pilkington, M. (2017). Can Blockchain Technology Help Promote New Tourism Destinations? The Example of Medical

$42 \quad$ Journal of E-Technology Volume 9 Number 2 May 2018


Tourism in Moldova.

[20] Poulsen, L. H. (2014, 04 22). Liberal Alliance holder e-valg med bitcoin-teknologi. Retrieved from Version2.DK: https:// www.version2.dk/artikel/liberal-alliance-holder-e-valg-med-bitcoin-teknologi-57645

[21] Republic of Estonia e-Residency. (2017, 11 22). e-Residency - New Digital Nation. Retrieved from https://e-resident.gov.ee/ [22] Schumpeter, J. (1942). Capitalism, Socialism and Democracy. New York: Harper.

[23] Sharma, P. K., Moon, S. Y., Park, J. H. (2017). Block-VN: A Distributed Blockchain Based Vehicular Network Architecture in Smart City. Journal of information processing systems, 13(1) 184-195.

[24] Sun, J., Yan, J., Zhang, K. Z. (2016). Blockchain-based sharing services: What blockchain technology can contribute to smart cities. Financial Innovation, 2(1) 26.

[25] Tapscott, D., Tapscott, A. (2016). Blockchain Revolution: How the technology behind Bitcoin is changing money, business, and the world. New York: Penguin.

[26] Watanabe, H., Fujimura, S., Nakadaira, A., Miyazaki, Y., Akutsu, A., Kishigami, J. (2016). Blockchain contract: Securing a blockchain applied to smart contracts. 2016 IEEE International Conference In Consumer Electronics (ICCE), (p. 467-468).

[27] Wright, A., De Filippi, P. (2015). Decentralized blockchain technology and the rise of lex cryptographia.

[28] Zhang, Y., Wen, J. (2017). The IoT electric business model: Using blockchain technology for the internet of things. Peer-toPeer Networking and Applications, 10(4) 983-994. 